\title{
Vertex markers: modification of grid methods as markers to reproduce large size augmented reality objects to afford hands
}

\author{
Wahyu Teja Kusuma, Ahmad Afif Supianto, Herman Tolle \\ Computer Science Faculty, Brawijaya University, Indonesia
}

\begin{tabular}{l}
\hline \hline Article Info \\
\hline Article history: \\
Received May 27, 2019 \\
Revised Oct 10, 2019 \\
Accepted Oct 18, 2019 \\
\hline Keywords: \\
Augmented reality \\
Grid method \\
Marker \\
Reproduce size \\
Vertex marker
\end{tabular}

\begin{abstract}
Marker Based Augmented Reality means technology that can present digital content in the real world based on markers. The weakness of the research on developing Marker Based Augmented Reality applications found is using small digital content. Weakness is caused by the area of view of Augmented Reality cameras is limited by the placement of markers that are affordable to the user's hand. The fundamental contribution and advantage of this study to modifying the Grid method become a vertex marker for reproducing a large digital object accurately and can be reached by hand when displayed. Finally, the accuracy testing revealed continous of pieces of digital objects that showed by vertex markers are accurate.
\end{abstract}

Copyright () 2020 Institute of Advanced Engineering and Science. All rights reserved.

Corresponding Author:

Wahyu Teja Kusuma,

Computer Science Faculty,

Brawijaya University,

Malang, Indonesia.

Email: tejawahyu@gmail.com

\section{INTRODUCTION}

Augmented Reality is a technology that can present digital content into the real world. Users can interact with digital and real-world content simultaneously through a smartphone screen in real time. Therefore, in the application development stage, it is necessary to activate the Augmented Reality camera. Marker Based Augmented Reality means technology that can present digital content in the real world based on markers. Markers serve as a reference system to determine the position and orientation of digital content. Therefore, the Augmented Reality system will first detect the marker to determine the position and orientation of the digital content that is to be displayed.

The weakness of the previous research on developing Marker Based Augmented Reality applications can only use small digital content. This weakness occurs because the area of view of Augmented Reality cameras is limited by the placement of markers that are affordable to the user's hand [1]. In the field of Teaching and learning, markers in the form of images on the pages of books, tables of chemical elements, or attached to learning media that cause the size of the digital object displayed to adjust the place [2-11]. In the field of Product and Marketing, customers usually immediately try to use the product and want to get more interactive information [12-21]. The illustration of marker weaknesses from the previous research is shown in Figure 1.

The ideal condition when running the Marker Based Augmented Reality application is when the camera can capture markers, as shown in Figure 1 (a) and (b). Whereas in Figure 1 (c) it is not an ideal condition, because markers are outside the viewing area of the camera that causes digital objects cannot be displayed. Based on these problems, the idea is to reproduce large digital objects become affordable. Reproducing means cutting large digital objects into many parts and markers on each piece must be able to 
display digital objects as if they were connecting or remaining intact. The key to the continousity between pieces of digital objects to remain intact is accuracy.

Based on the literature review, effective methods have been found to reproduce images with an emphasis on accuracy, called the Grid method [22-24]. The Grid method is a way of drawing using horizontal and vertical auxiliary lines called edge. The Grid can be drawn, printed, or pasted on top of the reference image and canvas. Then, how to reproduce it is done by completing one cell. With techniques like this, the accuracy in each box can be immediately known. Finally, the results of this study is done by accuracy testing of the continousity between pieces of digital objects that showed by vertex markers.

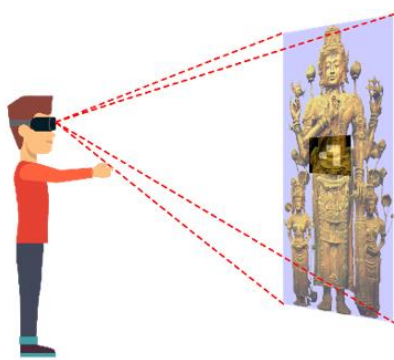

(a)

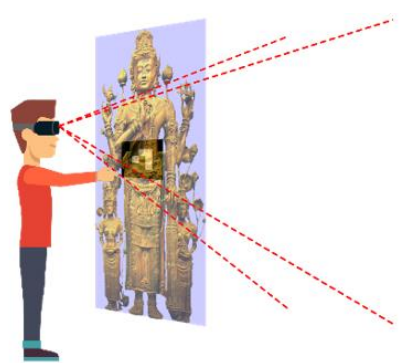

(b)

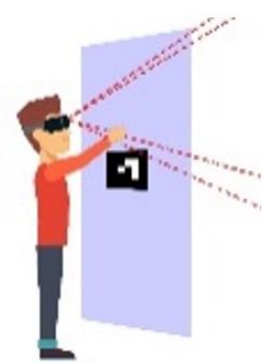

(c)

Figure 1. Illustration of the weaknesses of the previous research

\section{PRELIMINARY RESEARCH}

Preliminary research aims to validate the maximum size of digital objects that can be displayed in the Marker Based Augmented Reality application within the user's hand. The reach of the user's hand is a long shoulder-grip forward. The reach of the hands of the Indonesian population is shown to be $65.7 \mathrm{~cm}$ maximum [25]. Research to get the maximum size of digital objects is done by measuring distances that are directly proportional to the area of view of the camera. Where the $\mathrm{x}$-axis is the length of the digital object, the y-axis is the height of the digital object, and the z-axis is the distance of the marker with the camera. Research design is shown in Figure 2 (a). Figure 2 (b) shows that to be able to capture all parts of the object measuring A1, the camera must be $\geq 100 \mathrm{~cm}$ apart with digital objects. Figure 2 (c). shows the maximum size of the digital object that can be captured by the camera at the distance of the reach of the Indonesian population is $\leq 77 \times 54$.

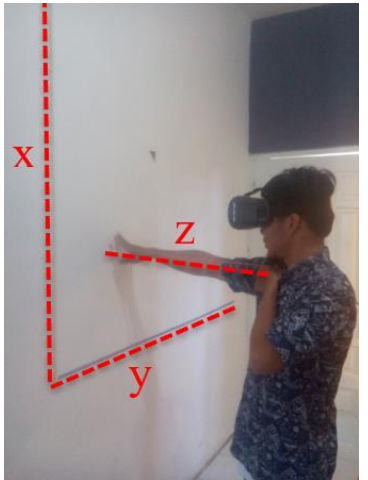

(a)

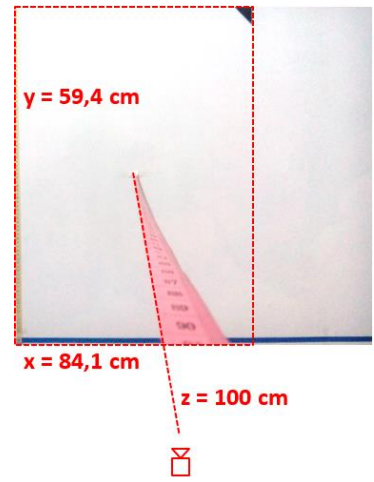

(b)

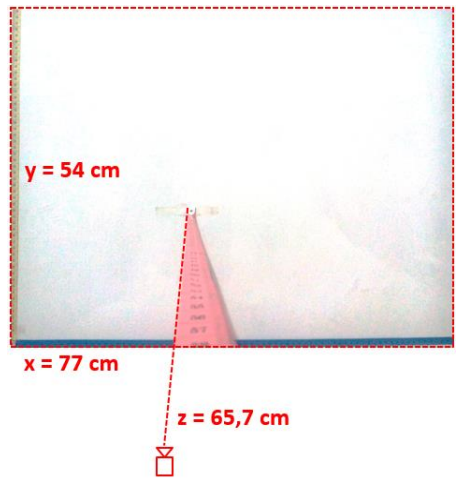

(c)

Figure 2. Preliminary research designs

\section{PROPOSED METHOD}

This study produced a vertex marker. Vertex markers are designed in the development of Marker Based Augmented Reality applications can use large digital objects that are still affordable. Vertex markers are the result of modifying the Grid method. The method for producing vertex markers by Figure 3 . 


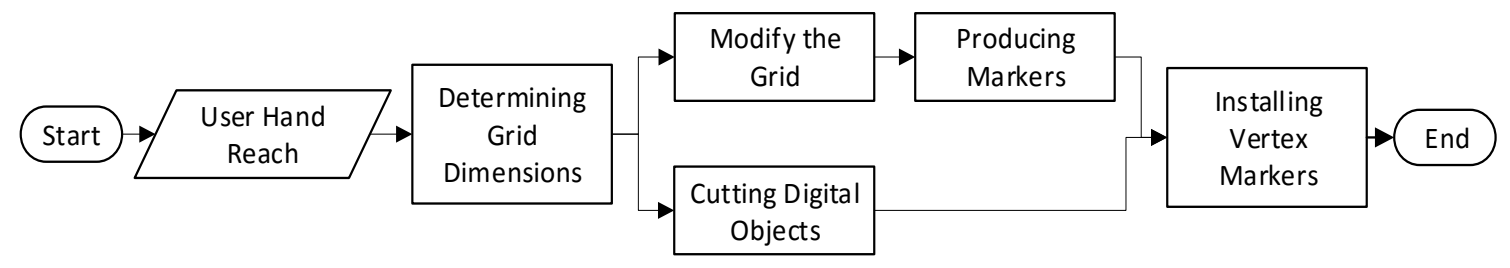

Figure 3. Flow diagram of method for producing vertex markers

\subsection{User hand reach}

The reach of the user's hand is a long shoulder-grip forward. The reach of the users in this study uses data on the reach of the Indonesian population. The hand coverage data of the Indonesian population used is the maximum hand reach calculated from 10-49 years old [25].

\subsection{Determining grid dimensions}

Determining the Grid dimension begins by determining the size of the cell to be used. The measurement method of a cell is shown in preliminary research. The cell size obtained is equal to the maximum area of view of the camera at the ideal distance of the smartphone with the user's eye within the user's reach. Based on the results of the preliminary research, the cell size limit that can be used by the developer is $\leq 77 \times 54 \mathrm{~cm}$. Based on the size of one cell, then the Grid dimension is determined to divide large digital objects. Dimensions Grid divides large digital objects into many cells from columns multiplied by rows.

\subsection{Cutting digital objects}

Cutting large digital objects aims to produce pieces of digital objects with a size of $\leq 77 \times 54 \mathrm{~cm}$. Cutting large digital objects is done using the Grid method. The reference for cutting large digital objects is the edge of the Grid. Cutting digital objects is done using Adobe Photoshop as shown in Figure 4.

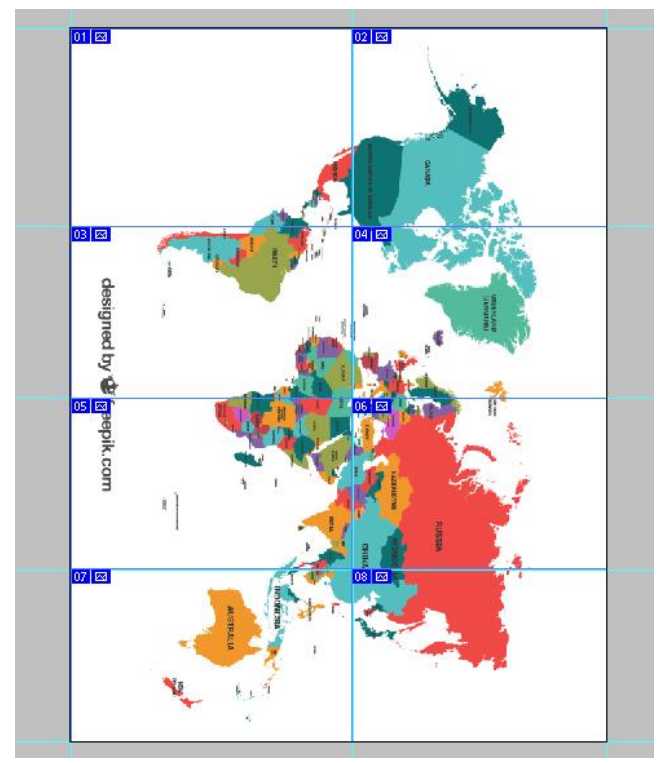

Figure 4. Cutting digital objects using the grid method

\subsection{Modifying the grid}

Modifying the Grid is done by removing edges and maintaining the vertex. Edge must be removed, because if it is not removed, then the Grid is still intact. As a result, the whole Grid is still considered as a whole marker by the application. This phase of removing the edge leaves a vertex. Vertex is used as a reference for the placement of markers. The result of Grid modification is shown in Figure 5.

Vertex markers: modification of grid methods as markers to reproduce large size... (Wahyu Teja Kusuma) 


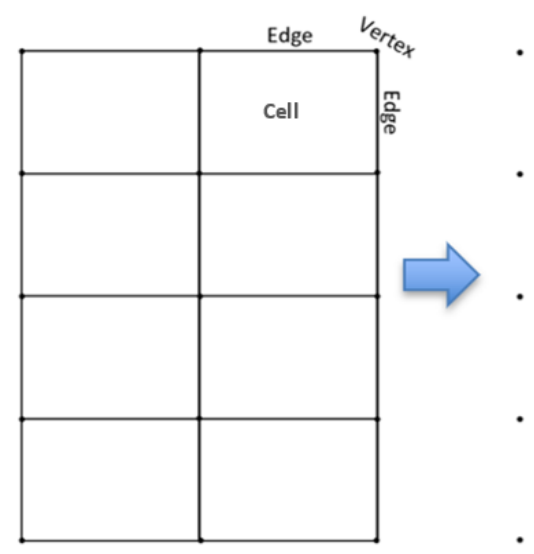

Figure 5. The result of grid modification

\subsection{Producing markers}

Producing vertex markers is done using the Adobe Photoshop application. Vertex markers are produced using the Grayscale image format. Images produced for markers can be anything. There is no specification of the specified image. In this study the image used as a marker is a white alphabet in a black square. The production of images used for markers is shown in Figure 6.

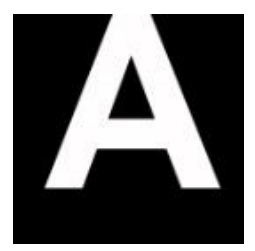

Figure 6. Production of drawings for markers

\subsection{Installing vertex markers}

Installation of markers using vertex as a reference is shown in Figure. Each cell has four vertex markers. This means that to display digital objects, Augmented Reality cameras must capture all four vertex markers in one cell. The illustration of the vertex marker installation is shown in Figure 7.

A

ப]

[G

J

山
B

보

H

$\mathbf{K}$

N
C

$\mathbf{F}$

1

$\mathbf{L}$

【o

Figure 7. Vertex marker installation 


\section{RESULTS AND DISCUSSIONS}

After the preliminary research and modification of the Grid method became a marker, then the next step is to implement and test accuracy. This study uses a Grid method implemented to cut digital objects with A1 size into many A4 sized pieces. Therefore, in this case using a Grid with a 2x4 dimension, which means it produces eight cells. Each cell has four markers. These four markers are called vertex markers. The implementation of vertex markers is shown in Figure 8.

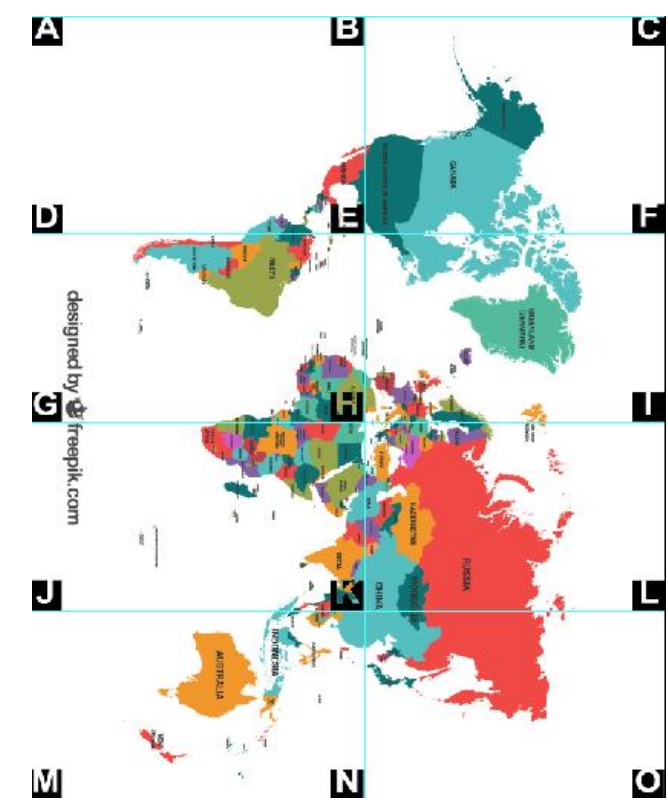

Figure 8. Use of vertex markers

An accurate vertex marker is when large digital objects that have been cut into pieces can be displayed as if they were intact. To find out the accuracy of the vertex marker, accuracy testing was carried out using the Marker Based Augmented Reality application. Active Augmented Reality cameras are used to capture vertex markers to prove the continousity accuracy of the pieces of digital objects displayed on the screen. Accuracy testing is done using a smartphone that has the specifications of the Android 4.4.2 operating system, a $5 \mathrm{MP}$ camera with landscape orientation, $1.3 \mathrm{GHz}$ quad-core processor, 4.5 inches touchscreen LCD $16 \mathrm{M}$ colors, and 1 GB RAM.

Accuracy testing is done by using range restrictions from the hands of the Indonesian population grouped by age that shown in Table 1 . Table 2 shows that the maximum number of inputs that can be captured by the camera is as many as 4 cells or 4 vertex markers. Therefore, the accuracy testing is done three times to cover all vertex markers. The $2 \times 4$ Grid used in this case produces 10 contacts. The results of the accuracy analysis in Table 3 show that the continousity between pieces of digital objects in all intersections is accurate. The results of this accuracy test confirm that this study succeeded in modifying the Grid method to be a vertex marker that can be relied upon to accurately reproduce large digital objects.

Table 1. Accuracy of testing limit

\begin{tabular}{ccc}
\hline Age Group & Maximum Hand Reach Average [5] & Maximum Coverage Area of the Camera \\
\hline $10-14$ & $52.79 \mathrm{~cm}$ & 2 cells \\
$15-19$ & $62.44 \mathrm{~cm}$ & 4 cells \\
$20-24$ & $64.24 \mathrm{~cm}$ & 4 cells \\
$25-29$ & $63.86 \mathrm{~cm}$ & 4 cells \\
$30-34$ & $65.66 \mathrm{~cm}$ & 4 cells \\
$35-39$ & $61.98 \mathrm{~cm}$ & 4 cells \\
$40-44$ & $65.66 \mathrm{~cm}$ & 4 cells \\
$45-49$ & $65.7 \mathrm{~cm}$ & 4 cells \\
\hline
\end{tabular}


Table 2. Accuracy of testing

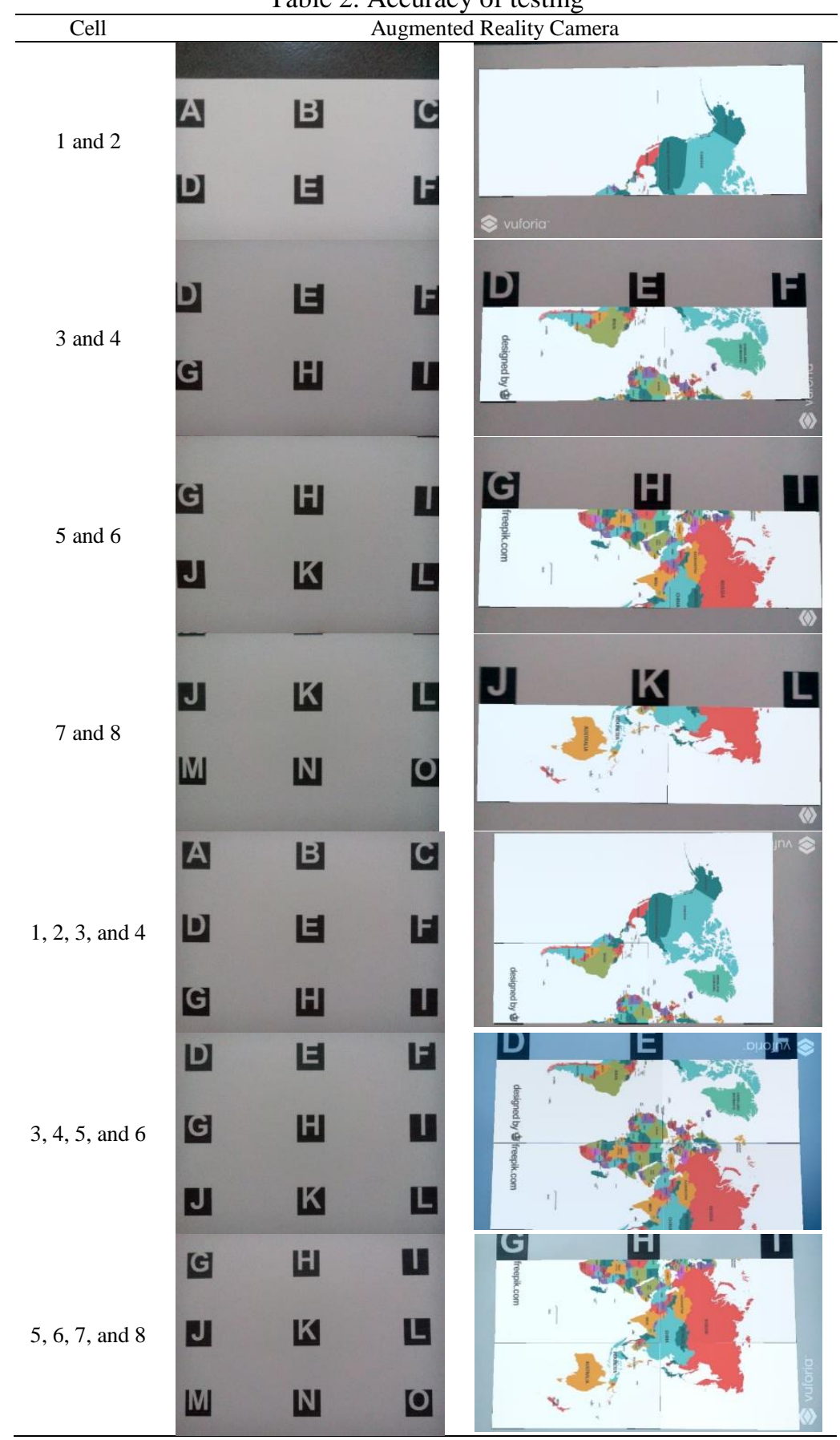

Table 3. Analyze the accuracy of contact between pieces of digital object

\begin{tabular}{ccc}
\hline No & Cell Contact & Continousity of Digital Objects Pieces \\
\hline 1 & Cell: 1-2 and 2-1 & Accurate \\
2 & Cell: 1-3 and 3-1 & Accurate \\
3 & Cell: 2-4 and 4-2 & Accurate \\
4 & Cell: 3-4 and 4-3 & Accurate \\
5 & Cell: 3-5 and 5-3 & Accurate \\
6 & Cell: 4-6 and 6-4 & Accurate \\
7 & Cell: 5-6 and 6-5 & Accurate \\
8 & Cell: 5-7 and 7-5 & Accurate \\
9 & Cell: 6-8 and 8-6 & Accurate \\
10 & Cell: 7-8 and 8-7 & Accurate \\
\hline
\end{tabular}




\section{CONCLUSION}

This study succeeded in modifying the Grid method to become a vertex marker. Vertex markers inherit the advantages of the Grid method. Therefore, the vertex markers can be used to reproduce large digital objects accurately and can be reached by hand when displayed. The fundamental contributions and advantages of the vertex marker are innovations in the field of Marker Based Augmented Reality research.

\section{ACKNOWLEDGEMENTS}

This research is supported by the Faculty of Computer Science, Brawijaya University.

\section{REFERENCES}

[1] D. Yulianto, R. Hartanto, and P. I. Santosa, "An Interactive Book With Augmented Reality For Learning The Cirebon Mask Dance," INFOTEL, vol. 10, 2018.

[2] D. S. Abhijitsinh Jadeja, Richa Mehta, "New Era of Teaching Learning: 3D Marker Based Augmented Reality," Int. J. Inf. Sci. Tech., vol. 6, 2016.

[3] C. Lytridis, A. Tsinakos, and I. Kazanidis, "ARTutor-An Augmented Reality Platform for Interactive Distance Learning," Multidiscip. Digit. Publ. Inst., 2018.

[4] Z. Taçgin, N. Uluçay, And E. Özüağ, "Designing and Developing an Augmented Reality Application: A Sample of Chemistry Education," J. Turkish Chem. Soc., vol. Cilt 1, no. Sayı 1, p. Sayfa 147-164., 2016.

[5] A. Setiawan, S. Rostianingsih, and T. R. Widodo, "Augmented reality application for chemical bonding based on android," International Journal of Electrical and Computer Engineering (IJECE), vol. 9(1), pp. 445-451, 2019.

[6] D. Vora, D. Udeshi, T. Bhatti, A. Desai, and N. Lade, "Marker Based Augmented Reality Techniques: Review," IOSR J. Eng., vol. 3, 2018.

[7] A. Maiti, A. D. Maxwell, and A. A. Kist, "Using Marker based Augmented Reality and Natural User Interface for Interactive Remote Experiments," IEEE, 2017.

[8] M. F. Norraji and M. S. Sunar, "wARna - Mobile-based Augmented Reality Colouring Book," IEEE, 2015.

[9] R. Layona, B. Yulianto, and Y. Tunardi, "Web based Augmented Reality for Human Body Anatomy Learning," Elsevier Ltd, 2018.

[10] H. Pradibta, “Augmented Reality: Daily Prayers for Preschooler Student,” iJIM, vol. 12, 2018.

[11] F. A. Aziz, F. Abdullah, and L. L. Win, "Using Marker Based Augmented Reality for Training in Automotive Industry," Int. J. Recent Technol. Eng., vol. 7, 2018.

[12] D. Adrianto, F. A. Luwinda, and V. Yesmaya, "Augmented Reality Implementation in Watch Catalog as E-Marketing Based on Mobile Aplication," Int. Conf. Comput. Appl. Informatics, 2016.

[13] L. meng Chun, H. Arshad, S. S. M. Nizam, and S. A. A. Shukri, "A Usability Evaluation of an Interactive Application for Halal Products Using Optical Character Recognition and Augmented Reality Technologies," 2nd Int. Conf. Appl. Sci. Technol., 2017.

[14] M. Dimitris and M. Doukas, "A Web-based Platform for Customer Integration in the Decentralised Manufacturing of Personalised Products," Elsevier, 2012.

[15] L. W. Shang, M. H. Zakaria, and I. Ahmad, "Mobile Phone Augmented Reality Postcard," J. Telecommun. Electron. Comput. Eng., vol. 8, 2016.

[16] A. F. Waruwu, I. P. A. Bayupati, and I. K. G. D. Putra, "Augmented Reality Mobile Application of Balinese Hindu Temples: DewataAR,” I. J. Comput. Netw. Inf. Secur., vol. 2, pp. 59-66, 2015.

[17] S. Izzaty, H. Tolle, R. Dermawi, and F. Permana, "Augmented reality objects design in augmented story book mobile application for better engagement," International Journal of Electrical and Computer Engineering (IJECE), vol. 9(1), pp. 570-576, 2019.

[18] W. Li, A. Y. C. Nee, and S. K. Ong, "A State-of-the-Art Review of Augmented Reality in Engineering Analysis and Simulation," Multimodal Technol. Interact. MDPI, 2017.

[19] D. E. Kurniawan, A. Dzikri, and M. Suriya, "Object Visualization Using Maps Marker Based On Augmented Reality," IEEE, 2018.

[20] C. H. Chen, C.-H. Ho, and J.-B. Lin, "The development of an augmented reality game-based learning environment," Elsevier Ltd, 2015.

[21] A. D. W. Utami and F. Nadziroh, "Implementasi Teknologi Augmented Reality dalam Visualisasi Ibadah Umrah Menggunakan Metode Marker Based Tracking pada Android," INFORM, vol. 4, 2019.

[22] H. South, "Drawing and Copying Pictures Using a Grid," ThoughtCo., 2017. [Online]. Available: https://www.thoughtco.com/grid-drawing-overview-1123090. [Accessed: 13-Nov-2018].

[23] T. McArdle, "The Grid Method," Art is Fun, 2018. [Online]. Available: https://www.art-is-fun.com/grid-method/. [Accessed: 13-Nov-2018].

[24] B. A. Flowers, "Grid-Based Outdoor Object Recognition For Augmented Reality," University of Rhode Island, 2014.

[25] A. Indonesia, “Antropometri Indonesia (Indonesian Anthropometry-in Bahasa),” 2018. 